(two patient groups and control group). In group A patients with isolated cyanotic congenital heart disease were enrolled. Group B consisted of the patients with cyanotic congenital heart disease with other concomitant diseases. Group C included the healthy control group. For the neurodevelopmental evaluation Bayley Scale of Infant Development- II was used.

Results Thirty eight patients (32 in group A and 6 in group B) and 33 healthy subjects in group $\mathrm{C}$ were included in the study. Mean age of the patient group was 22,5 $\pm 11,2$ months. In group A the mental developmental index (MDI) $(82,5 \pm 14,7)$ was significantly lower than group C $(92,3 \pm 6,9)(\mathrm{p}=0,001)$. Similarly the psychmotor developmental index (PDI) in group A $(82,0 \pm 18,2)$ was found significantly lower than group $C(92,5$ $\pm 7,4)(\mathrm{p}=0,003)$. When group A and B were compared, mean MDI and PDI scores were lower in group B, but the difference was not statistically significant. For group A, according to the psycomotor development index $48,6 \%$ of the patients were found mild to severe retarded. In terms of the mental development index, $34,4 \%$ of the pateints were with moderate or mild retardation.

Conclusions Mental-motor retardation is frequently encountered in children with cyanotic congenital heart disease. For this reason, these children have to be under regular follow up for neurodevelopmental status.

\section{PS-025 ESTIMATION OF USEFULNESS OF NON-INVASIVE CARDIOVASCULAR DIAGNOSTIC SCREENING METHODS IN EARLY DETECTION OF CRITICAL CONGENITAL HEART DEFECTS IN NEWBORNS}

${ }^{1}$ W Blaz, ${ }^{2}$ W Kawalec, ${ }^{1}$ E Homa, ${ }^{1} \mathrm{~A}$ Szadkowska, ${ }^{2} \mathrm{~A}$ Turska-Kmiec, ${ }^{2} \mathrm{M}$ Zuk. ${ }^{1}$ Neonatology and NICU, Provincial Hospital, Rzeszów, Poland; ${ }^{2}$ Cardiology, Children's Memorial Health Institute, Warszawa, Poland

\subsection{6/archdischild-2014-307384.320}

Prevalence of critical congenital heart defects (CCHD) is 1.5-3/ 1000 newborns. Early discharge from nurseries may postpone CCHD detection. There is a search for additional screening modalities for early diagnosis of CCHD.

Aim 1. Estimation of usefulness of physical examination (PE), pulse oximetry (POX) and echocardiography $(\mathrm{ECHO})$ in $\mathrm{CCHD}$ screening detection

2. Evaluation of parents' attitude to POX as CCHD diagnostic screening modality

Methods PE, POX, ECHO were done in all well newborns born during two year period in one hospital. PE was performed routinely, POX was done $>24$ th hour of life (cut-off $<95 \%$ ). ECHO was carried out before discharge in asymptomatic newborns or after abnormal PE or POX. Statistical analysis was performed.

Results Among 4589 babies, 311 were excluded. CHD was diagnosed in 103 newborns. CCHD was detected in 10 newborns $(2.3 / 1000)$ based on: PE in 5, POX in 9, and ECHO in 10. Pulse oximetry approval questionnaire showed that $95 \%$ of mothers

\begin{tabular}{|c|c|c|c|c|c|c|c|}
\hline & $\begin{array}{l}\text { Sensitivity } \\
(\%)\end{array}$ & $\begin{array}{l}\text { Specificity } \\
(\%)\end{array}$ & $\begin{array}{l}\text { PPV } \\
(\%)\end{array}$ & $\begin{array}{l}\text { NPV } \\
(\%)\end{array}$ & LR+ & LR- & $\begin{array}{l}\text { ROC } \\
\text { AUC }\end{array}$ \\
\hline PE & 50 & 100 & 100 & 98,8 & - & 0,5 & 0,74 \\
\hline POX & 90 & 99,9 & 69,2 & 99,9 & 900 & 0,1 & 0,95 \\
\hline ECHO & 100 & 100 & 100 & 100 & - & 0 & 0,98 \\
\hline
\end{tabular}

participated in the study without hesitation and more than $99 \%$ approved the idea of implementing population pulse oximetry screening.

Conclusions

1. PE supported by POX provide optimal early neonatal CCHD detection screening.

2. Screening ECHO detects insignificant cardiovascular problems, leading to unnecessary follow-up.

3. POX as the CCHD screening test is unanimously accepted by parents.

\section{PS-026 CEREBRAL AND RENAL OXYGEN SATURATION AND EXTRACTION IN NEONATES WITH LEFT VENTRICULAR OUTFLOW TRACT OBSTRUCTION}

${ }^{1}$ MJ Mebius, ${ }^{1}$ ME van der Laan, ${ }^{2}$ MTR Roofthooft, ${ }^{2}$ RMF Berger, ${ }^{1}$ AF Bos, ${ }^{1} E M W$ Kooi. ${ }^{1}$ Department of Neonatology, Beatrix Children's Hospital/University Medical Center Groningen, Groningen, Netherlands; ${ }^{2}$ Department of Pediatric Cardiology, Beatrix Children's Hospital/University Medical Center Groningen, Groningen, Netherlands

\subsection{6/archdischild-2014-307384.321}

Background and aim Neonates with left ventricular outflow tract obstruction (LVOTO) are at risk of developing brain damage, due to either ischemia or hypoxemia. Our aim was to explore the differences in cerebral and renal tissue oxygen saturation $\left(\mathrm{rSO}_{2}\right)$ and extraction (FTOE) between neonates with LVOTO with or without compromised antegrade ascending aortic flow.

Methods We included fourteen neonates with LVOTO and categorised them into neonates with compromised antegrade ascending aortic flow (hypoplastic left heart syndrome $(n=6)$ ) and neonates without compromised antegrade ascending aortic flow (coarctatio aortae $(\mathrm{n}=7) /$ non-critical aortic valve stenosis $(\mathrm{n}=$ 1)). We measured cerebral and renal $\mathrm{rSO}_{2}$ using near-infrared spectroscopy during $72 \mathrm{~h}$. Simultaneously, we measured preductal arterial oxygen saturation $\left(\mathrm{SpO}_{2}\right)$ and calculated FTOE.

Results On day 1, neonates with compromised antegrade ascending aortic flow had lower cerebral $\mathrm{rSO}_{2}$ than neonates without compromised antegrade ascending aortic flow (median $\mathrm{rSO}_{2} 68.5 \%$ vs. $79.4 \%$, p-value $=0.032$ ). Furthermore, cerebral FTOE tended to be higher in neonates with compromised antegrade ascending aortic flow on day 1 (median FTOE 0.30 vs. 0.14 , $\mathrm{p}$-value $=0.086$ ). Significant differences in cerebral $\mathrm{rSO}_{2}$ and FTOE disappeared the following days. There were no differences in $\mathrm{SpO}_{2}$, renal $\mathrm{rSO}_{2}$ and FTOE between both groups.

Conclusions Because there were no differences in $\mathrm{SpO}_{2}$ between both groups, and cerebral FTOE tended to be higher in neonates with compromised antegrade ascending aortic flow, the lower cerebral oxygen saturation might be due to ischemia rather than hypoxemia. Furthermore, in neonates with antegrade ascending aortic flow, cerebral oxygenation might be spared.

\section{PS-027 STRATIFICATION OF COMPLEXITY IN CONGENITAL HEART SURGERY: COMPARISON BETWEEN RACHS-1 (RISK ADJUSTMENT FOR CONGENITAL HEART SURGERY), ARISTOTLE AND STS-EACTS METHODS}

PE Ferraz Cavalcanti, MPBO Sá, CA Santos, IM Esmeraldo, ML Chaves, RFA Lins, RC Lima. Cardiovascular Surgery, Pronto Socorro Cardiológico de Pernambuco, Recife, Brazil

10.1136/archdischild-2014-307384.322 
Background and aims To determine whether stratification of complexity methods in congenital heart surgery (RACHS-1, Aristotle and STS-EACTS) fit to our centre and determine the best method in discriminating hospital mortality.

Methods Surgical procedures in patients under 18 age were allocated to the categories proposed by the three methods currently available. The outcome in-hospital mortality was calculated for each category. Statistical analysis using the chi-square Pearson test was performed to verify whether the categories presented different mortalities. The categories' discriminatory ability of each method was determined by calculating the area under the ROC curve and a comparison between the curves was performed.

Results 360 patients were allocated by the 3 methods. There was a statistically significant difference between the mortality categories: RACHS -1(1) - 1.3\%; (2) - 11.4\%; (3) - 27.3\%; (4) $50 \%$, $(\mathrm{p}<0.001)$, Aristotle (1) - 1.1\%; (2) - 12.2\%; (3) - 34\%, (4) - 64.7\%, (p < 0.001) and STS - EACTS (1) - 5,5\%, (2) $13.6 \%,(3)-18.7 \%,(4)-35.8 \%$, ( $<0.001)$. The three methods had similar accuracy by calculating the area under the ROC curve (RACHS - 1-0.738; STAT - 0.739; Aristotle - 0.766).

Conclusion The three methods of stratification of complexity currently available in the literature are useful with different mortalities among the proposed categories and similar discriminatory capacity for in-hospital mortality in our centre.

\section{PS-028 NEUROCOGNITION IN CHILDREN WITH CONGENITAL HEART DISEASE: A SYSTEMATIC REVIEW AND META-ANALYSIS}

${ }^{1} \mathrm{C}$ Sterken, ${ }^{1} \mathrm{~J}$ Vundelinckx, 'D Mesotten, ${ }^{2} \mathrm{~J}$ Lemiere. ${ }^{1}$ Department of Intensive Care Medicine, Catholic University of Leuven, Leuven, Belgium; ${ }^{2}$ Child and Adolescent Psychiatry \& Paediatric Haemato-Oncology, University Hospitals Leuven, Leuven, Belgium

\subsection{6/archdischild-2014-307384.323}

Background and objective Children with congenital heart disease (CHD) may experience difficulties in academic and daily life functioning. Intelligence and neurocognitive skills have been associated with these difficulties. The aim of this systematic review and meta-analysis is to assess intelligence in comparison with neurocognitive skills, like memory, attention and executive functions, in children with CHD.

Methods A comprehensive search of electronic databases PubMed, Embase and Cochrane was conducted for studies measuring intelligence, memory, attention and executive functions in children with CHD. Standardised mean differences (SMD's) between the CHD-group and a healthy control group were calculated for these neurocognitive functions.

Results 28 studies were retrieved, of which 10 tested a healthy control group. Children with CHD (median age 7.4 years; median sample size 20) scored worse than healthy control children for all investigated neurocognitive functions. A medium effect size was found for intelligence (SMD $=-0.53$ [95\% CI: -0.71 to -0.35$] \mathrm{p}<0.00001)$. Effect sizes, ranging from -0.41 to -0.53 , were similar for memory, global executive function and non-reaction time measures of attention and executive functions. Executive function reaction time had the largest effect size (SMD $=0.76$ [95\% CI: 0.48 to 1.05$] ; \mathrm{p}<$ 0.00001).

Conclusions Children with CHD risk lower performance on intelligence and neurocognitive skills. Only executive function reaction time showed a large effect size. A high diversity in research practices and small sample sizes were also ascertained. Large, more standardised, long-term follow-up studies of neurocognitive skills are required for a better understanding of these deficits and their impact on daily life functioning.

\section{PS-029 THE EFFECT OF CONGENITAL CYANOTIC AND ACYANOTIC HEART DISEASE (CHD) ON INTRAUTERINE GROWTH}

A Soliman, E Shatlah, A Sabt, F Alyafei, M Alqadi, A Adel. Pediatrics, Hamad Medical Centre, Doha, Qatar

\subsection{6/archdischild-2014-307384.324}

Introduction The heart-placental axis utilises many common molecules and genes and reflects intimate and synergistic growth of both organs. Abnormal cardiac development leading to CHD can be associated with abnormal placentation and abnormal transfer of nutrients and oxygen.

Objectives We measured the anthropometric parameters (length, weight and head circumference) and the placental weight of 49 FT newborns (gestation period $>36$ weeks) infants with CHD $\{$ (cyanotic $(n=8)$ and acyanotic $(n=41)\}$ diagnosed clinically and by echocardiography and compared these data with those for randomly selected normal FT newborns $(\mathrm{n}=104)$.

Results Newborn infants with CHD were significantly shorter and had lower birth weight and smaller head size compared to normal newborns. Their placental weights were significantly decreased compared to those for normal newborns. However, there was no statistically significant difference in the anthropometric parameters of infants with cyanotic versus acyanotic heart disease.

Discussion The intrauterine growth restriction in newborn infants with CHD may represent an adaptive mechanism to cope with the compromised perfusion caused by the congenital cardiac anomaly. However, this restricted growth can pose a risk for postnatal development in these infants.

Conclusion In this study CHD was associated with significant affection of birth weight, length and head circumference and lower placental weight compared to normal newborns.

\section{Abstract PS-029 Table 1}

\begin{tabular}{|c|c|c|c|c|}
\hline & Placntal wt (g) & Birth Wt (g) & Birth length $(\mathrm{cm})$ & Head circumf (cm) \\
\hline N ormal newborns $n=104$ & 677.6 & 3185.3 & 50.6 & 34.0 \\
\hline CHD newborns $n=49$ & $597.3 *$ & $2600 *$ & $46.4^{*}$ & $31.7 *$ \\
\hline Acya notic $n=41$ & 588.64 & 2510.0 & 45.98 & 31.51 \\
\hline Cyanotic $=n=8$ & 640.00 & 2870.0 & 48.56 & 32.69 \\
\hline
\end{tabular}

